Pacific Journal of Mathematics

A COMMUTATIVITY THEOREM FOR NON-ASSOCIATIVE
ALGEBRAS OVER A PRINCIPAL IDEAL DOMAIN 


\title{
A COMMUTATIVITY THEOREM FOR NON-ASSOCIATIVE ALGEBRAS OVER A PRINCIPAL IDEAL DOMAIN
}

\author{
Jiang Luh and Mohan S. Putcha
}

Let $A$ be an algebra (not necessarily associative) over a principal ideal domain $R$ such that for all $a, b \in A$, there exist $\alpha, \beta \in R$ such that $(\alpha, \beta)=1$ and $\alpha a b=\beta b a$. It is shown that $A$ is commutative.

Throughout this paper $N$ will denote the set of natural numbers and $Z^{+}$the set of positive integers. $A$ will denote an algebra with identity 1 over a Principal Ideal Domain $R$. If $a, b \in A$ then $[a, b]=a b-b a$. If $\alpha, \beta \in R$, then $(\alpha, \beta)$ denotes the greatest common divisor of $\alpha$ and $\beta$. If $a \in A$, then the order of $a, o(a)$ is the generator of the ideal $I=\{\alpha \mid a \in R, \alpha a=0\}$ of $R . \quad o(a)$ is unique up to associates. As a generalization of concepts in [1], [2], [3], [4], [5] we consider the following:

(*) For all $a, b \in A$, there exist $\alpha, \beta \in R$ such that $(\alpha, \beta)=1$ and $\alpha a b=\beta b a$.

We will show that if $A$ satisfies (*), then $A$ is commutative. This generalizes [3; Theorem 3.5].

Lemma 1. Let $p$ be a prime in $R, m \in Z^{+}$such that $p^{m} A=(0)$. If A satisfies (*), then $A$ is commutative.

Proof. Let $C$ denote the center of $A$. Let $x \in A, o(x)=p^{k}$, $k \in N$. We prove by induction on $k$ that $x \in C$. If $k=0$, then $x=0$. So let $k>0$. Let $y \in A$. First we show

$$
[x, y] \neq 0 \quad \text { implies } \quad[y x, y]=0 .
$$

If $y x=0$, this is trivial. So let $y x \neq 0$. Now for some $\alpha_{1}, \alpha_{2} \in R$,

$$
\begin{aligned}
& \alpha_{1} x y=\alpha_{2} y x,\left(\alpha_{1}, \alpha_{2}\right)=1 \\
& \beta_{1}(x+1) y=\beta_{2} y(x+1),\left(\beta_{1} \beta_{2}\right)=1 .
\end{aligned}
$$

So $\alpha_{1} \beta_{1}(x+1) y=\alpha_{1} \beta_{2} y(x+1)$. Thus substituting the above, we get

$$
\left(\alpha_{2} \beta_{1}-\alpha_{1} \beta_{2}\right) y x=\left(\alpha_{1} \beta_{2}-\alpha_{1} \beta_{1}\right) y .
$$


We claim that $\left(\alpha_{2} \beta_{1}-\alpha_{1} \beta_{2}\right) y x \neq 0$. For otherwise $\left(\alpha_{1} \beta_{2}-\alpha_{1} \beta_{1}\right) y=$ 0 . Since $y \neq 0$, we get $p \mid \alpha_{1} \beta_{2}-\alpha_{1} \beta_{1}$.

Also $\left(\alpha_{1} \beta_{2}-\alpha_{1} \beta_{1}\right) y x=0$. Since $\left(\alpha_{2} \beta_{1}-\alpha_{1} \beta_{2}\right) y x=0$, we get $\left(\alpha_{2}-\alpha_{1}\right) \beta_{1} y x=0$. Since $y x \neq 0, p \mid \beta_{1}\left(\alpha_{2}-\alpha_{1}\right)$. So

$$
p\left|\alpha_{1}\left(\beta_{2}-\beta_{1}\right), p\right| \beta_{1}\left(\alpha_{2}-\alpha_{1}\right) \text {. }
$$

Case 1. $p \nmid \alpha_{1}$. Then since $\alpha_{1}\left(\beta_{2}-\beta_{1}\right) y=0$, we get $\left(\beta_{2}-\beta_{1}\right) y=$ 0 . So by (2), $\beta_{1}[x, y]=0=\beta_{2}[x, y]$. Since $[x, y] \neq 0$, we get $p \mid \beta_{1}$, $p \mid \beta_{2}$, contradicting (2).

Case 2. $p \mid \alpha_{1}$. Then $p \nmid \alpha_{2}$ and so $p \nmid \alpha_{2}-\alpha_{1}$. Thus $p \mid \beta_{1}$. So $p \nmid \beta_{2}, p \nmid \beta_{2}-\beta_{1}$. Since $\alpha_{1}\left(\beta_{2}-\beta_{1}\right) y=0$ we get $\alpha_{1} y=0$. So $\alpha_{1} x y=$ 0 . By (2), $\alpha_{2} y x=0$. Since $y x \neq 0$, we get $p \mid \alpha_{2}$, a contradiction.

Hence by (3)

$$
\left(\alpha_{2} \beta_{1}-\alpha_{1} \beta_{2}\right) y x \neq 0
$$

In particular

So

$$
\alpha_{2} \beta_{1}-\alpha_{1} \beta_{2} \neq 0
$$

$$
\alpha_{2} \beta_{1}-\alpha_{1} \beta_{2}=p^{t} \delta, t \in N, \delta \in R,(\delta, p)=1 .
$$

If $t \geqq k$, then $\left(\alpha_{2} \beta_{1}-\alpha_{1} \beta_{2}\right) y x=0$, a contradiction. So $t<k$. Hence

$$
p^{k-t}\left(\alpha_{1} \beta_{2}-\alpha_{1} \beta_{1}\right) y=p^{k-t} p^{t} \delta y x=0 .
$$

Let $o(y)=p^{i}, i \in N$. If $i<k$, then $y \in C$, a contradiction. So $i \geqq$ $k$. Hence

$$
p^{k}\left|p^{i}\right| p^{k-t}\left(\alpha_{1} \beta_{2}-\alpha_{1} \beta_{1}\right)
$$

So $p^{t} \mid \alpha_{2} \beta_{2}-\alpha_{1} \beta_{1}$ and $\alpha_{1} \beta_{2}-\alpha_{1} \beta_{1}=p^{t} \gamma, \quad \gamma \in R$. Then $p^{t} \delta y x=$ $p^{t} \gamma y$. Hence $p^{t}(\delta y x-\gamma y)=0$. By induction hypothesis, $\delta y x-\gamma y \in$ $C$. So $[\delta y x-\gamma y, y]=0$. Thus $\delta[y x, y]=0$. Since $(\delta, p)=1,[y x, y]=$ 0 . This establishes (1).

Now let $u \in A$ and suppose $[x, u] \neq 0$. Then also $[x, u+1] \neq 0$. By $(1), \quad[u x, u]=0=[(u+1) x, u]$. So $[x, u]=0$, a contradiction. So $x \in C$ and the lemma is proved.

Lemma 2. Suppose $A$ satisfies (*). Let $a, b \in A, o(b)=0$. If $b a=0$, then $a b=0$. 
Proof. Suppose $a b \neq 0$. Then there exist $\beta_{1}, \beta_{2}, \gamma_{1}, \gamma_{2} \in R$ such that

$$
\begin{aligned}
& \beta_{1}(a+1) b=\beta_{2} b(a+1),\left(\beta_{1}, \beta_{2}\right)=1, \\
& \gamma_{1} a(b+1)=\gamma_{2} b(a+1),\left(\gamma_{1}, \gamma_{2}\right)=1 .
\end{aligned}
$$

So

$$
\beta_{1} a b=\left(\beta_{2}-\beta_{1}\right) b \text { and } \quad\left(\gamma_{2}-\gamma_{1}\right) a=\gamma_{1} a b
$$

If $\beta_{2}=\beta_{1}$, then $\beta_{1}, \beta_{2}$ are units and by (5) $a b=b a=0$, a contradiction. So $\beta_{2}-\beta_{1} \neq 0$. Similarly $\gamma_{2}-\gamma_{1} \neq 0$. Since $o(b)=0$, we get by (5) that $o(a b)=0$. So $o(a)=0$. Hence by (5), $\beta_{1} \neq 0$, $\gamma_{1} \neq 0$. Also by (5) $\left[\beta_{1} a b, b\right]=0$.

So

$$
\begin{aligned}
\left(\gamma_{2}-\gamma_{1}\right) \beta_{1} a b & =\gamma_{1} \beta_{1}(a b) b \\
& =\gamma_{1} \beta_{1} b(a b) \\
& =\beta_{1}\left(\gamma_{2}-\gamma_{1}\right) b a \\
& =0 .
\end{aligned}
$$

So $o(a b) \neq 0$, a contradiction. This proves the lemma.

Lemma 3. Suppose A satisfies (*). Let $b \in A, o(b)=0$. Then $b \in C$, the center of $A$.

Proof. Let $a \in A$. There exist $\alpha_{1}, \alpha_{2}, \beta_{1}, \beta_{2} \in R$ such that

$$
\begin{aligned}
& \alpha_{1} a b=\alpha_{2} b a,\left(\alpha_{1}, \alpha_{2}\right)=1, \\
& \beta_{1}(a+1) b=\beta_{2} b(a+1),\left(\beta_{1}, \beta_{2}\right)=1 .
\end{aligned}
$$

Multiplying the second equation by $\alpha_{1}$ and substituting the first we obtain

$$
b\left[\left(\alpha_{2} \beta_{1}-\alpha_{1} \beta_{2}\right) a-\left(\alpha_{1} \beta_{2}-\alpha_{1} \beta_{1}\right) \cdot 1\right]=0 .
$$

By Lemma 2,

$$
\left[\left(\alpha_{2} \beta_{1}-\alpha_{1} \beta_{2}\right) a-\left(\alpha_{1} \beta_{2}-\alpha_{1} \beta_{1}\right) \cdot 1\right] b=0 .
$$

Let $\mu=\alpha_{2} \beta_{1}-\alpha_{1} \beta_{2}$. Then $\alpha_{1}\left(\beta_{2}-\beta_{1}\right) b=\mu a b=\mu b a$. By (6) $\alpha_{1} \mu a b=$ $\alpha_{2} \mu b a=\alpha_{2} \mu a b$. So 


$$
\left(\alpha_{2}-\alpha_{1}\right) \alpha_{1}\left(\beta_{2}-\beta_{1}\right) b=0 \text {. }
$$

Since $o(b)=0$, we obtain by (6) that either $\alpha_{1}=\alpha_{2}$ is a unit, $\beta_{1}=\beta_{2}$ is a unit or else $\alpha_{1}=0$. The first two cases imply by (6) that $a b=$ $b a$. So let $\alpha_{1}=0$. Then $\alpha_{2} b a=0$ and $\alpha_{2}$ is a unit by (6). So $b a=$ 0 . By Lemma 2, $a b=0$. Thus in any case $a b=b a$ and we are done.

TheORem 4. Suppose A satisfies (*). Then A is commutative.

Proof. Suppose $A$ is not commutative. We will obtain a contradiction. There exists $x \in A$ such that $x \notin C$, the center of $A$. So $x+1 \notin C$. By Lemma $3 \quad o(x) \neq 0$ and $o(x+1) \neq 0$. Hence $o(1) \neq 0$. Let $o(1)=d \neq 0$. Then $d$ is not a unit and hence $d=$ $p_{1}^{\alpha_{1}} \cdots p_{t}^{\alpha_{t}}$ for some primes $p_{1}, \cdots, p_{t} \in A$ and some positive integers $\alpha_{1}, \cdots, \alpha_{t}$. Let $A_{i}=\left\{a \mid a \in A, p_{t}^{\alpha_{i}} a=0\right\}$. Then each $A_{t}$ is a nonzero subalgebra of $A$ and $A=A_{1} \oplus \cdots \oplus A_{t}$. Being subalgebras of $A$, the $A_{\imath}$ 's also satisfy (*). Being homomorphic images of $A$, all the $A_{1}$ 's have identity elements. By Lemma 1 each $A_{\imath}$ and hence $A$ is commutative, a contradiction. This proves the theorem.

\section{REFERENCES}

1. R. Coughlin and M. Rich, On scalar dependent algebras, Canad. J. Math., 24 (1972), 696-702.

2. R. Coughlin, E. Kleinfeld, and M. Rich, Scalar dependent algebras, Proc. Amer. Math. Soc., 39 (1973), 69-73.

3. K. Koh, J. Luh and M. S. Putcha, On the associativity and commutativity of algebras over commutative rings, Pacific J. Math., 63 (1976), 423-430.

4. M. Rich, A commutativity theorem for algebras, Amer. Math. Monthly, 82 (1975), 377-379.

5. J. C. K. Wang and J. Luh, The structure of a certain class of rings, Math. Japon., 20 (1975), 149-157.

Received October 5, 1976. The second author was partially supported by NSF Grant MCS 76-05784.

North Carolina State University

RALEIGH, NC 27607 


\section{PACIFIC JOURNAL OF MATHEMATICS}

\section{EDITORS}

RichaRd ARENS (Managing Editor)

University of California

Los Angeles, CA 90024

\section{R. A. Beaumont}

University of Washington

Seattle, WA 98105

C. C. Moore

University of California

Berkeley, CA 94720
J. DugunduI

Department of Mathematics

University of Southern California

Los Angeles, CA 90007

R. Finn AND J. Milgram

Stanford University

Stanford, CA 94305

\section{ASSOCIATE EDITORS}
E. F. BECKENBACH
B. H. NeumanN
F. WOLF
K. YoshidA

\section{SUPPORTING INSTITUTIONS}

UNIVERSITY OF BRITISH COLUMBIA

CALIFORNIA INSTITUTE OF TECHNOLOGY

UNIVERSITY OF CALIFORNIA

MONTANA STATE UNIVERSITY

UNIVERSITY OF NEVADA

NEW MEXICO STATE UNIVERSITY

OREGON STATE UNIVERSITY

UNIVERSITY OF OREGON

OSAKA UNIVERSITY

\author{
UNIVERSITY OF SOUTHERN CALIFORNIA \\ STANFORD UNIVERSITY \\ UNIVERSITY OF HAWAII \\ UNIVERSITY OF TOKYO \\ UNIVERSITY OF UTAH \\ WASHINGTON STATE UNIVERSITY \\ UNIVERSITY OF WASHINGTON \\ AMERICAN MATHEMATICAL SOCIETY
}

The Supporting Institutions listed above contribute to the cost of publication of this Journal, but they are not owners or publishers and have no responsibility for its contents or policies.

Mathematical papers intended for publication in the Pacific Journal of Mathematics should be in typed form or offset-reproduced (not dittoed), double spaced with large margins. Underline Greek letters in red, German in green, and script in blue. The first paragraph or two must be capable of being used separately as a synopsis of the entire paper. Items of the bibliography should not be cited there unless absolutely necessary, in which case they must be identified by author and Journal, rather than by item number. Manuscripts, in duplicate, may be sent to any one of the four editors. Please classify according to the scheme of Math. Reviews, Index to Vol. 39. All other communications should be addressed to the managing editor, or Elaine Barth, University of California, Los Angeles, California, 90024.

100 reprints are provided free for each article, only if page charges have been substantially paid. Additional copies may be obtained at cost in multiples of 50 .

The Pacific Journal of Mathematics is issued monthly as of January 1966. Regular subscription rate: $\$ 72.00$ a year (6 Vols., 12 issues). Special rate: $\$ 36.00$ a year to individual members of supporting institutions.

Subscriptions, orders for back numbers, and changes of address should be sent to Pacific Journal of Mathematics, 103 Highland Boulevard, Berkeley, California, 94708.

PUBLISHED BY PACIFIC JOURNAL OF MATHEMATICS, A NON-PROFIT CORPORATION

Printed at Jerusalem Academic Press, POB 2390, Jerusalem, Israel. 


\section{Pacific Journal of Mathematics}

Vol. 68, No. 2

April, 1977

William Allen Adkins, Aldo Andreotti and John Vincent Leahy, An analogue of Oka's theorem for weakly normal complex spaces ........

Ann K. Boyle, M. G. Deshpande and Edmund H. Feller, On nonsingularly

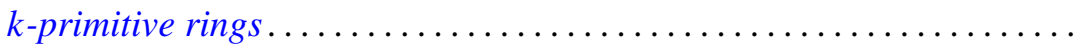

Rolando Basim Chuaqui, Measures invariant under a group of

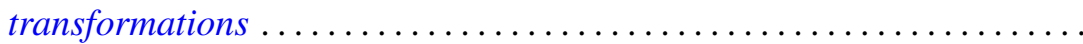

Wendell Dan Curtis and Forrest Miller, Gauge groups and classification of bundles with simple structural group .......................

Garret J. Etgen and Willie Taylor, The essential uniqueness of bounded nonoscillatory solutions of certain even order differential equations

Paul Ezust, On a representation theory for ideal systems

Richard Carl Gilbert, The deficiency index of a third order operator ........

John Norman Ginsburg, $S$-spaces in countably compact spaces using Ostaszewski's method.

Basil Gordon and S. P. Mohanty, On a theorem of Delaunay and some

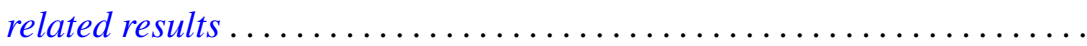

Douglas Lloyd Grant, Topological groups which satisfy an open mapping

theorem.

Charles Lemuel Hagopian, A characterization of solenoids

Kyong Taik Hahn, On completeness of the Bergman metric and its

subordinate metrics. II .

G. Hochschild and David Wheeler Wigner, Abstractly split group extensions.

Gary S. Itzkowitz, Inner invariant subspaces ...............

Jiang Luh and Mohan S. Putcha, A commutativity theorem for

non-associative algebras over a principal ideal domain.

Donald J. Newman and A. R. Reddy, Addendum to: "Rational approximation of $e^{-x}$ on the positive real axis".....

Akio Osada, On the distribution of a-points of a strongly annular function ....

Jeffrey Lynn Spielman, A characterization of the Gaussian distribution in a Hilbert space. .

Robert Moffatt Stephenson Jr., Symmetrizable-closed spaces ...

Peter George Trotter and Takayuki Tamura, Completely semisimple inverse $\Delta$-semigroups admitting principal series . . . . . . . .

Charles Irvin Vinsonhaler and William Jennings Wickless, Torsion free abelian groups quasi-projective over their endomorphism rings...

Frank Arvey Wattenberg, Topologies on the set of closed subsets ... 